\title{
Variations of helium and radon concentrations in soil gases from an active fault zone in southern Taiwan
}

\author{
Ching-Chou $\mathrm{Fu}^{\mathrm{a}}$, Tsanyao Frank Yang ${ }^{\mathrm{a}, *}$, Jane Du ${ }^{\mathrm{b}}$, Vivek Walia ${ }^{\mathrm{c}}$, Yue-Gau Chen ${ }^{\mathrm{a}}$, \\ Tsung-Kwei Liu ${ }^{\mathrm{a}}$, Cheng-Hong Chen ${ }^{\mathrm{a}}$ \\ a Department of Geosciences, National Taiwan University, No. 1, Sec. 4, Roosevelt Road, Taipei 10617, Taiwan \\ ${ }^{\mathrm{b}}$ National Pingtung University of Science and Technology, Neipu, Pingtung 91201, Taiwan \\ ${ }^{\mathrm{c}}$ National Center for Research on Earthquake Engineering, NARL, Taipei 106, Taiwan
}

\begin{abstract}
Systematical analysis of soil-gas compositions was performed in the National Pingtung University of Science and Technology (NPUST) campus in southern Taiwan. The results show that the anomalous sites for helium, radon, nitrogen and carbon dioxide concentrations coincide with the surface trace of geological and geomorphological characteristics of the active Chaochou Fault. Some of these sites were chosen for soil helium and radon gas continuous monitoring at the suspected fault scarp. During a consecutive measurement for several months, a striking feature is that anomalously high concentrations appeared to be spike-like a few hours to a few days before the earthquakes. This result suggests that the variations in soil-gas compositions along the Chaochou Fault may reflect the regional crustal stress/strain changes prior to earthquakes. (C) 2008 Elsevier Ltd. All rights reserved.
\end{abstract}

Keywords: Soil-gas; Active fault; Earthquakes; NPUST campus; Taiwan

\section{Introduction}

The N-S trending Chaochou (CC) Fault is the most important geological structure in the studied area (Fig. 1) and has been regarded as a structure boundary between the Pingtung Plain and the Central Mountain Range in southern Taiwan. The Pingdingshan alluvial terrace is another structural unit in this area (Fig. 1), comprising mainly of uncemented sand, mud, gravels and pebbles. Previous studies revealed that, in addition to the CC Fault, there are several N-S trending fractural structures nearby (Fu et al., 2005). The active CC Fault is believed to cut through the campus of National Pingtung University of Science and Technology (NPUST) based on geomorphological, geological and geochemical studies.

Generally, gas compositions in air are entirely different from the deep-crust derived components. The soil gases from the deep fault/fracture zones that may provide conduits for the gases to migrate upward from the deep crust or mantle usually exhibit

\footnotetext{
* Corresponding author. Tel.: +88623366 5874; fax: +886223636095

E-mail address: tyyang@ntu.edu.tw (T.F. Yang).
}

a higher carrier gas flux with a higher rare gas concentration (Ciotoli et al., 1999; Yang et al., 2003; Walia et al., 2005a, 2008). Such gas compositions, especially at fault zones, often show significant variations in particular gas species and have been considered as one of the effective earthquake precursors (e.g., Chyi et al, 2005; Walia et al., 2005b; Yang et al., 2005, 2006b).

In this study, we use the technique of soil-gas method to systematically survey over an active fault zone in the NPUST campus on the Pingdingshan terrace, where a clear fault scarp is present. Meanwhile, some sensitive sites were chosen for continuous monitoring on the soil gas composition of helium, radon and carbon dioxide.

\section{Methods and results}

The spatial variation survey was carried out during a period under stable meteorological conditions from 11 to 15 August 2006. Soil-gas samples were systematically collected from the $200-300 \mathrm{~m}$ spacing grid in an area of about $1.2 \times 2.3 \mathrm{~km}^{2}$ (Fig. 2). A total of 82 samples were collected using a hollow 


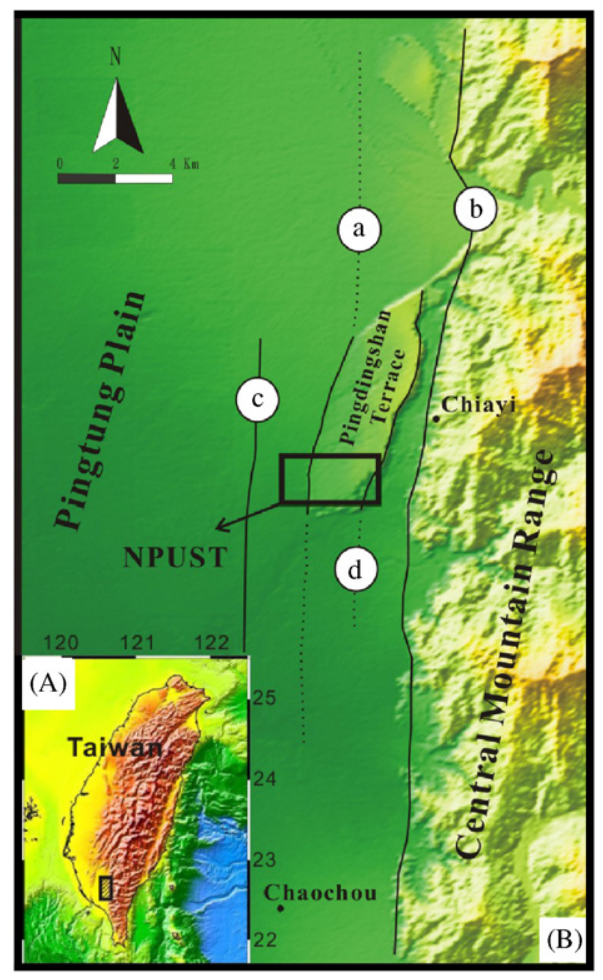

Fig. 1. (A) Topographical map of Taiwan and the relative position of the studied area. (B) Simplified structure map in the vicinity of the NPUST campus marked as rectangle. The major faults in this region are labeled as: $a$ : the Chaochou Fault; $b$ : the Chiayi Fault; $c$ : the Wanlong Fault; $d$ : the Pingdingshan Fault.

steel probe of $3 \mathrm{~cm}$ diameter and $130 \mathrm{~cm}$ length that was inserted into the soil at the depth of about $100 \mathrm{~cm}$. Following the method described by $\mathrm{Fu}$ et al. (2005), helium, radon and other gases such as carbon dioxide, methane, argon, oxygen and nitrogen from the sample bags were analyzed within a few hours after sampling by a helium leak detector (ASM100HDS, Alcatel), radon detector (RTM 2100, SARAD) and micro gas chromatography (CP4900, Varian), respectively. In general, the average analytical uncertainty is about $5 \%$ for most gases; however, it may be up to $10 \%$ for a trace amount of helium and radon concentration.

No detectable methane concentration was observed; meanwhile, argon and oxygen did not show significant variations. Therefore, only the results of major gases of nitrogen and carbon dioxide and the trace gases of helium and radon are discussed. The samples show a wide range of gas compositions: $\mathrm{N}_{2}$ ranges from $77.69 \pm 3.88$ to $89.99 \pm 4.50 \% ; \mathrm{CO}_{2}$ from $0.0 \%$ to $9.27 \pm 0.46 \%$; He from $5.24 \pm 0.02$ to $5.35 \pm 0.02 \mathrm{ppm}$; and Rn from $4.3 \pm 0.4 \times 10^{3}$ to $27.2 \pm 2.7 \times 10^{3} \mathrm{~Bq} / \mathrm{m}^{3}$.

Compared with the air composition, the soil-gas samples exhibit much higher $\mathrm{CO}_{2}$ and $\mathrm{Rn}$ concentrations, and also excess contents of $\mathrm{N}_{2}$ and $\mathrm{He}$. We use $\Delta \mathrm{He}$ and $\Delta \mathrm{N}_{2}$ to indicate the excess contents of the analyzed data in this study $\left(\Delta \mathrm{He}=\left([\mathrm{He}]_{\text {sample }}-[\mathrm{He}]_{\mathrm{air}}\right) ; \Delta \mathrm{N}_{2}=\left(\left[\mathrm{N}_{2}\right]_{\text {sample }}-\left[\mathrm{N}_{2}\right]_{\text {air }}\right) ;\right.$ and $\left.[\mathrm{He}]_{\mathrm{air}}=5.24 \mathrm{ppm},\left[\mathrm{N}_{2}\right]_{\mathrm{air}}=78.08 \%\right)$. Furthermore, to recognize the anomalous data, the threshold values are set as the mean values plus two standard deviation of the data set, in which anomalously high values are not included. Accordingly, the threshold values set for $\Delta \mathrm{He}, \mathrm{Rn}, \Delta \mathrm{N}_{2}$ and $\mathrm{CO}_{2}$ are $0.06 \mathrm{ppm}, 14.7 \times 10^{3} \mathrm{~Bq} / \mathrm{m}^{3}, 3.10 \%$ and $4.20 \%$, respectively. Fig. 2 shows the distribution of the soil-gas compositions, in which the thick cross symbols indicate those sites exhibiting anomalies relative to the threshold values.

\section{Discussion and conclusions}

\subsection{Spatial variations in soil gases}

Although many factors may affect the soil-gas compositions, we minimize the influences of meteorological factor and soil types in this work by sampling within a short period under similar weather conditions and at similar soil types. The buried fault and fractures in the area, which can provide pathway for deep gas sources, are considered as the most likely reasons to generate the anomalies for soil gases.

Fig. 2 shows the location of sampling sites and the contour map of soil-gas compositions. There are two clear N-S linear anomalies for helium concentrations (Fig. 2a), which can be correlated well with the trace of the fault scarps in NPUST campus (lines $a$ and $d$ shown in Fig. 1, respectively). Soil $\mathrm{N}_{2}$ and $\mathrm{Rn}$ anomalous values also show similar $\mathrm{N}-\mathrm{S}$ trend with the He anomalous distribution (Fig. $2 \mathrm{~b}$ and c), although some points were not matched well for each other. Carbon isotopic data for $\mathrm{CO}_{2}$ in the soil samples range from $-11.8 \%$ to $-23.4 \%$ PDB, which can be interpreted as the result of mixing between organic sediments (ca. $-30 \%$ ) and limestone $(0 \%$ components in the studied area ( $\mathrm{Fu}$ et al., 2005). It can explain that some sites exhibit high carbon dioxide concentrations, which are derived from biogenic source, but no anomalies for other gases. On the other hand, the distribution of anomalous values of helium, radon and subordinately nitrogen match well with the trace of the fault scarps in the investigated area.

\subsection{Sources of soil gases}

Trace gases such as radon and helium usually can migrate toward the surface from deep sources together with their carrier gases, e.g., $\mathrm{CO}_{2}$ and $\mathrm{CH}_{4}$ (Etiope and Martinelli, 2002; Yang et al., 2003). There are many natural gases and mud volcanoes distributed along the tectonic structures in SW Taiwan (Yang et al., 2004) and the exhaling gases can serve as carrier gases for those trace gases. Nevertheless, unlike the gases from both offshore methane venting sites and onshore mud volcanoes showing very low radon concentrations (Yang et al., 2003, 2006a), the soil radon gases in this study exhibit higher concentrations than in those areas with hydrocarbon-rich venting gases.

Both carbon dioxide and nitrogen are the potential carrier gases for radon and helium gases at fault zones in this area. Nitrogen concentration shows very good correlation with helium concentration with a correlation coefficient of 0.7796 , suggesting that nitrogen could be the carrier gas for helium along the fault zones. In contrast, there is a very poor correlation $(0.2478)$ between carbon dioxide and helium concentration. As mentioned earlier, the carbon isotopic data demonstrate that carbon 

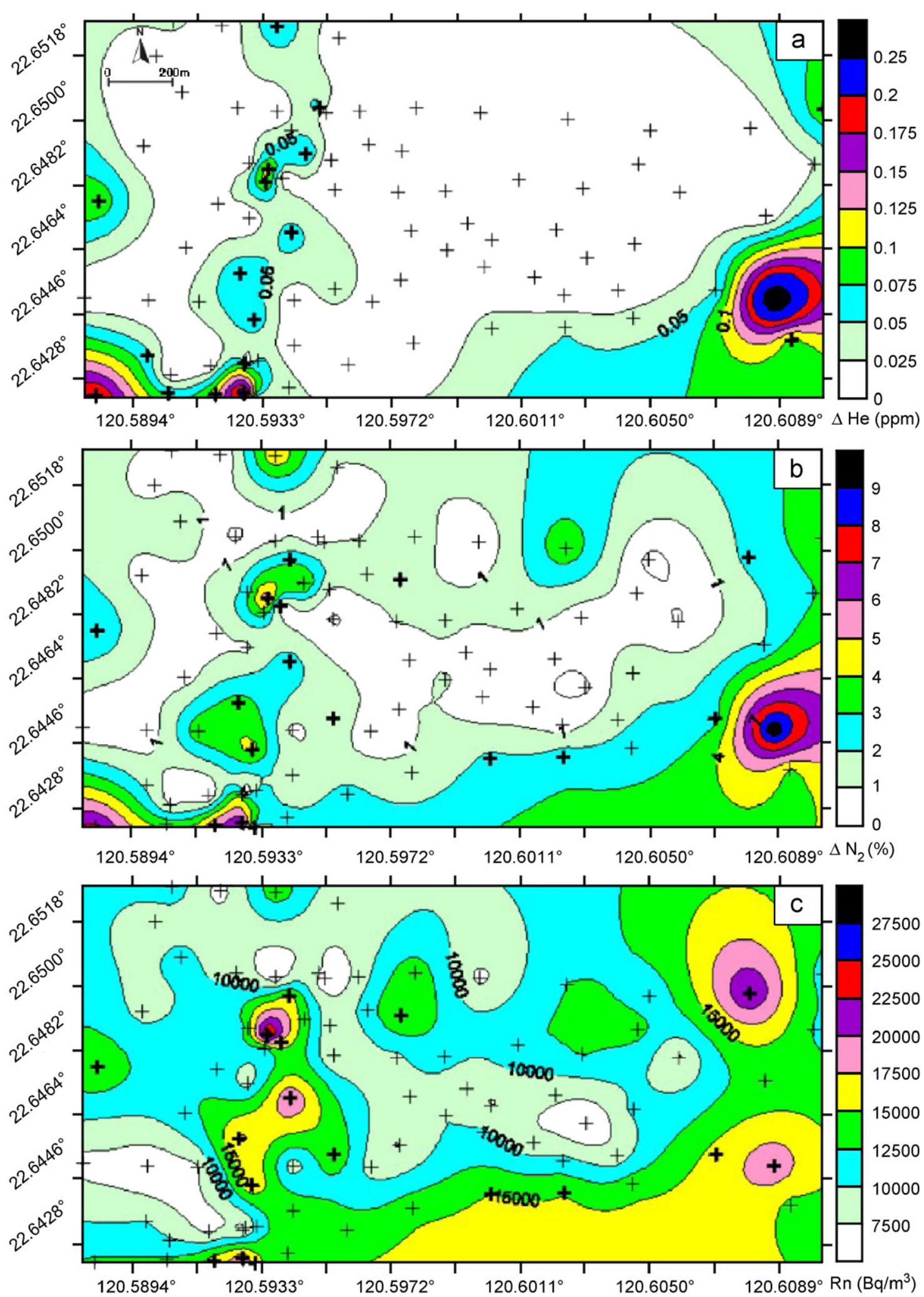

Fig. 2. Distribution of soil-gas anomalous sites in the study area for (a) $\mathrm{He}$, (b) $\mathrm{N}_{2}$ and (c) Rn. Cross symbol indicates the sampling site for the soil-gas survey in this study. The thick cross symbols indicate the sites exhibit anomalous soil-gas concentration.

dioxide could be the result of mixing between organic sediments and limestone components in the study area. They may be originated from the decomposition of organic matter or bio- genic source from shallow surface (Fu et al., 2005). Hence, $\mathrm{CO}_{2}$ may not be associated with high helium and radon concentrations, which usually are derived from deep gas sources. 


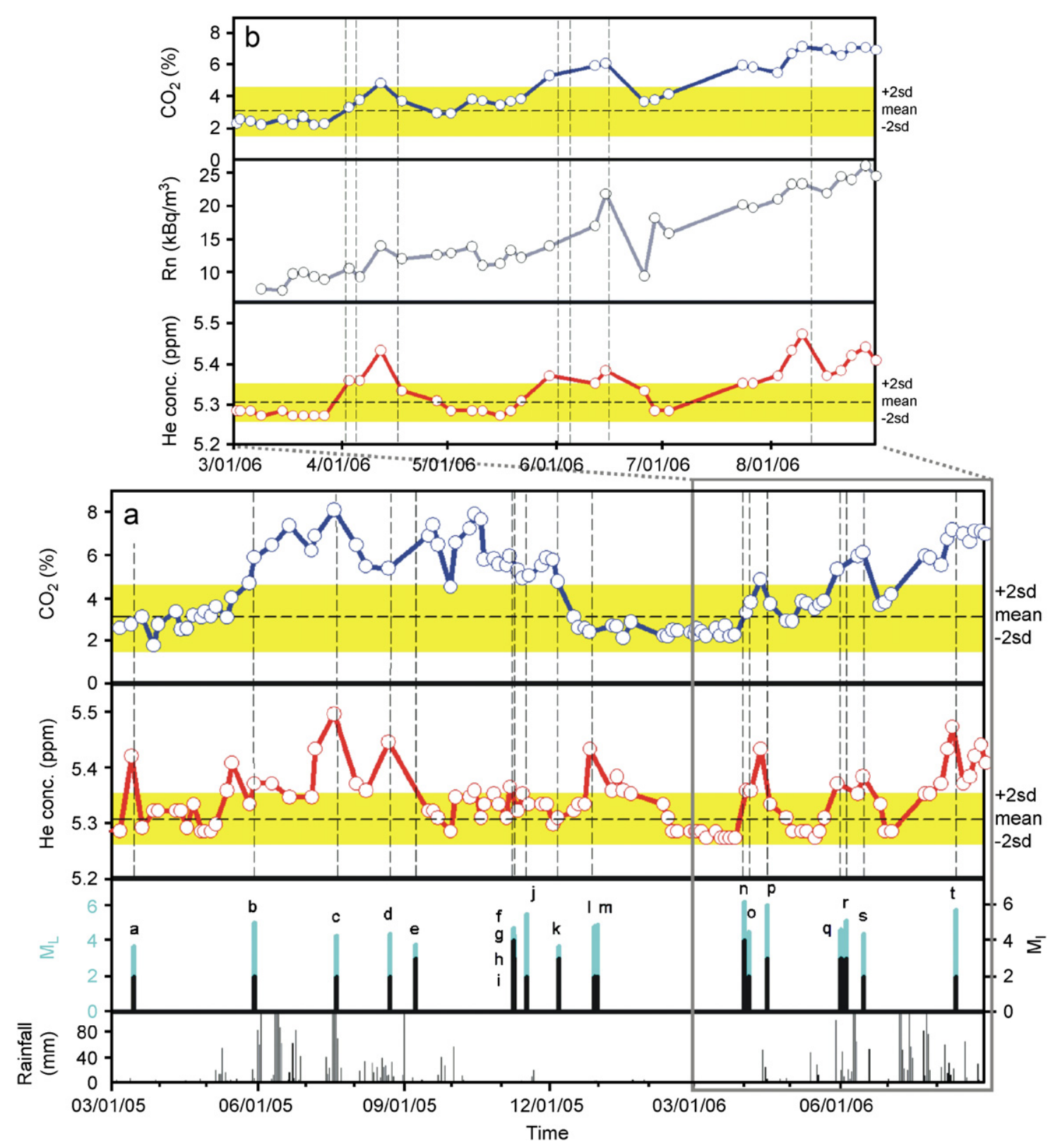

Fig. 3. Temporal variations in soil-gas concentrations during the time period of (a) 1 March 2005 to 31 August 2006, and (b) 1 March 2006 to 31 August 2006. Horizontal dashed line and the shadowed area indicate the mean and threshold (mean $\pm 2 \sigma$ ) of the gases. Rainfall and earthquake data are also plotted for comparison. Vertical dashed line indicates the earthquake event with marks shown in Table 1.

It is interesting to note that there are no good correlations for radon gas with both $\mathrm{N}_{2}$ and $\mathrm{CO}_{2}$ either (the coefficients are 0.4157 and 0.4176 , respectively). It implies that soil radon may be derived from different sources and carried out by both $\mathrm{N}_{2}$ and $\mathrm{CO}_{2}$ through fault zones from different source domains.

\subsection{Temporal variations in soil gases}

Some sensitive sites, which show higher concentrations in both major and trace gases, along the fault scarp in the NPUST campus were collected for continuous monitoring (Fu et al., 2005). The time series data of the soil gases can be divided into two groups as shown in Fig. 3. The first part was from 1st
March, 2005 to 28th February, 2006, in which we have only $\mathrm{CO}_{2}$ and $\mathrm{He}$ data (Fig. 3a). In the second part we were able to add Rn data from 1st March, 2006 to 31st August, 2006 (Fig. 3b).

The meteorological factor, i.e., rainfall in our case, seems to play a minor role in affecting the variations in soil $\mathrm{He}, \mathrm{Rn}$ and $\mathrm{CO}_{2}$ (Fig. 3a). Compiling all the felt earthquakes $\left(M_{\mathrm{L}} \geqslant 3.7\right.$; intensity $\geqslant 2$ ) occurred during the period of monitoring (Table 1); only the He anomalies correlated well with most earthquakes, except for three events, $e, j, k$, marked in Fig. 3a and Table 1.

It is interesting to note that there is a period with a high value of $\mathrm{CO}_{2}$ from 13th May, 2005 to 6th December, 2005 (Fig. 3a). The same pattern for both $\mathrm{CO}_{2}$ and $\mathrm{Rn}$ occurred again since 
Table 1

Catalog of related felt earthquakes occurred from 1st March, 2005 to 28th February, 2006 in Taiwan

\begin{tabular}{|c|c|c|c|c|c|c|c|c|}
\hline No. ${ }^{a}$ & Date & $\begin{array}{l}\text { Lat. } \\
\left({ }^{\circ} \mathrm{N}\right)\end{array}$ & $\begin{array}{l}\text { Long. } \\
\left({ }^{\circ} \mathrm{E}\right)\end{array}$ & $\begin{array}{l}\text { Depth } \\
(\mathrm{km})\end{array}$ & $\begin{array}{l}\text { Mag. } \\
\left(M_{\mathrm{L}}\right)\end{array}$ & $\begin{array}{l}\text { Int. } \\
\left(M_{\mathrm{I}}\right)\end{array}$ & $\begin{array}{l}\text { Distance } \\
(\mathrm{km})\end{array}$ & $\begin{array}{l}\Delta t^{\mathrm{b}} \\
\text { (day) }\end{array}$ \\
\hline $\mathrm{a}$ & $2005 / 3 / 1523: 53$ & 22.62 & 120.67 & 20.0 & 3.7 & 2 & 7.6 & 1.6 \\
\hline $\mathrm{b}$ & 2005/5/30 06:17 & 23.17 & 121.66 & 32.4 & 5.0 & 2 & 123.5 & 13.9 \\
\hline c & $2005 / 7 / 20 \quad 18: 48$ & 22.84 & 120.78 & 22.5 & 4.3 & 2 & 28.9 & 13.4 \\
\hline d & $2005 / 8 / 2305: 15$ & 22.50 & 120.97 & 13.6 & 4.4 & 2 & 41.1 & 0.8 \\
\hline $\mathrm{e}$ & $2005 / 9 / 8 \quad 04: 32$ & 22.85 & 120.67 & 18.0 & 3.8 & 3 & 24.36 & - \\
\hline $\mathrm{f}$ & 2005/11/8 13:48 & 22.85 & 120.67 & 13.6 & 4.4 & 4 & 24.4 & 0.2 \\
\hline g & 2005/11/8 13:49 & 22.87 & 120.68 & 9.7 & 4.7 & 4 & 26.8 & 0.2 \\
\hline $\mathrm{h}$ & $2005 / 11 / 8 \quad 13: 52$ & 22.87 & 120.67 & 11.6 & 3.7 & 3 & 26.5 & 0.2 \\
\hline $\mathrm{i}$ & 2005/11/8 17:08 & 22.85 & 120.66 & 15.4 & 4.3 & 3 & 24.1 & 0.3 \\
\hline $\mathrm{j}$ & 2005/11/16 17:14 & 21.90 & 121.77 & 133.2 & 5.5 & 2 & 145.8 & 2.3 \\
\hline $\mathrm{k}$ & $2005 / 12 / 6 \quad 14: 42$ & 22.83 & 120.69 & 16.2 & 3.7 & 3 & 23.0 & 0.2 \\
\hline 1 & 2005/12/29 06:17 & 22.94 & 121.15 & 20.5 & 4.8 & 2 & 65.5 & 2.9 \\
\hline $\mathrm{m}$ & 2005/12/31 05:07 & 22.55 & 121.13 & 54.8 & 4.9 & 2 & 55.3 & 4.8 \\
\hline $\mathrm{n}$ & 2006/4/1 18:02 & 22.88 & 121.08 & 7.2 & 6.2 & 4 & 55.9 & - \\
\hline o & $2006 / 4 / 414: 59$ & 22.88 & 121.13 & 7.7 & 4.5 & 2 & 60.51 & 1.3 \\
\hline $\mathrm{p}$ & 2006/4/16 06:40 & 22.86 & 121.30 & 17.9 & 6.0 & 3 & 75.8 & 4.0 \\
\hline$q$ & $2006 / 6 / 1 \quad 10: 26$ & 22.77 & 121.05 & 7.9 & 4.6 & 3 & 48.35 & 2.1 \\
\hline $\mathrm{r}$ & 2006/6/4 17:06 & 22.85 & 121.26 & 14.1 & 5.0 & 3 & 71.56 & 5.4 \\
\hline s & $2006 / 6 / 15$ 17:52 & 22.61 & 121.01 & 8.1 & 4.4 & 2 & 42.2 & 0.4 \\
\hline $\mathrm{t}$ & 2006/8/12 07:51 & 22.56 & 121.49 & 10.3 & 5.7 & 2 & 91.8 & 9.0 \\
\hline
\end{tabular}

${ }^{\mathrm{a}}$ The relevant anomalous peak marked in Fig. 3 .

${ }^{\mathrm{b}}$ Time difference between the peak of the anomaly and the earthquake event.

late June, 2006 (Fig. 3b). It is not clear if this kind of variations is due to the local biogenic activity or the seasonal variation by far. We shall envisage if the pattern will repeat again in the next rainy season in this area. Interestingly, $\mathrm{CO}_{2}$ and $\mathrm{Rn}$ concentrations at the monitoring site show good correlation (0.8753). It implies that $\mathrm{CO}_{2}$ could serve as a carrier gas for soil $\mathrm{Rn}$ at this site.

Plotting all the anomalous peaks with earthquake events through time (Fig. 3), it shows that about $90 \%$ of the events can be correlated to some precursory anomalous peaks a few hours to a few days before the event occurred (Table 1). Hence, the site is considered to be sensitive to the local crustal stress and thus suitable for continuous monitoring. However, some decoupled anomalous peaks occurred, i.e., not all the simultaneous gases showed anomalous peaks prior to the corresponding events. Longer continuous and more comprehensive monitoring is necessary to further understand the relationship between soil-gas variations and fault/earthquake activity in the area.

\section{Acknowledgments}

We thank P.S. Jiang, S.J. Lin, and K.W. Wu for their help in collecting and analyzing samples. Two anonymous reviewers gave critical comments and improved the paper. This work was financially supported by the Central Geological Survey (TFY/5226902000-06-95-02) and National Science Council (TFY/93-2119-M-002-027) of Taiwan.

\section{References}

Chyi, L.L., Quick, T.J., Yang, T.F., Chen, C.-H., 2005. Soil gas radon spectra and earthquakes. Terr. Atmos. Oceanic Sci 16, 763-774.
Ciotoli, G., Etiope, G., Guerra, M., Lombardi, S., 1999. The detection of concealed faults in the Ofanto Basin using correlation between soil-gas fracture survey. Tectonophysics 301, 321-332.

Etiope, G., Martinelli, G., 2002. Migration of carrier and trace gases in the geosphere: an overview. Phys. Earth Planet. Inter. 129, 185-204.

Fu, C.C., Yang, T.F., Walia, V., Chen, C.-H., 2005. Reconnaissance of soil gas composition over the buried fault and fracture zone in southern Taiwan. Geochem. J. 39, 427-439.

Walia, V., Su, T.C., Fu, C.C., Yang, T.F., 2005a. Spatial variations of radon and helium concentrations in soil gas across Shan-Chiao fault, northern Taiwan. Radiat. Meas. 40, 513-516.

Walia, V., Virk, H.S., Yang, T.F., Mahajan, S., Walia, M., Bajwa, B.S., 2005b. Earthquake prediction studies using radon as a precursor in $\mathrm{N}-\mathrm{W}$ Himalayas, India: a case study. Terr. Atmos. Oceanic Sci. 16, 775-804.

Walia, V., Mahajan, S., Kumar, A., Singh, S., Bajwa, B.S., Dhar, S., Yang, T.F., 2008. Fault delineation study using soil-gas method in Dharamsala area, NW Himalayas, India. Radiat. Meas., (this issue), doi: 10.1016/j.radmeas.2008.04.071.

Yang, T.F., Chou, C.Y., Chen, C.-H., Chyi, L.L., Jiang, J.H., 2003. Exhalation of radon and its carrier gases in SW Taiwan. Radiat. Meas. 36, 425-429.

Yang, T.F., Yeh, G.H., Fu, C.C., Wang, C.C., Lan, T.F., Lee, H.F., Chen, C.-H., Walia, V., Sung, Q.C., 2004. Composition and exhalation flux of gases from mud volcanoes in Taiwan. Environ. Geol. 46, 1003-1011.

Yang, T.F., Walia, V., Chyi, L.L., Fu, C.C., Wang, C.C., Chen, C.-H., Liu, T.K., Song, S.R., Lee, C.Y., Lee, M., 2005. Variations of soil radon and thoron concentrations in a fault zone and prospective earthquakes in SW Taiwan. Radiat. Meas. 40, 496-502.

Yang, T.F., Chuang, P.C., Lin, S., Chen, J.C., Wang, Y., Chung, S.H., 2006a. Methane venting in gas hydrate potential area offshore of SW Taiwan: evidence of gas analysis of water column samples. Terr. Atmos. Oceanic Sci. 17, 933-950.

Yang, T.F., Fu, C.C., Walia, V., Chen, C.-H., Chyi, L.L., Liu, T.K., Song, S.R., Lee, M., Lin, C.W., Lin, C.C., 2006b. Seismo-geochemical variations in SW Taiwan: multi-parameter automatic gas monitoring results. Pure Appl. Geophys. 163, 693-709. 